\title{
INSTRUMENTOS GERENCIAIS E O PROCESSO DE TOMADA DE DECISÃO: UM ESTUDO EM EMPRESAS DO SETOR DE AUTOPEÇAS EM BAYEUX/PB
}

\section{MANAGERIAL TOOLS AND DECISION MAKING PROCESS: A STUDY IN AUTO PARTS COMPANIES IN BAYEUX / PB}

\author{
Luiz Dias Pacheco Neto \\ Centro Universitário de João Pessoa- UNIPE \\ E-mail: luiz_diaspac@hotmail.com \\ Alan Santos de Oliveira \\ Universidade Federal do Ceará - UFC \\ E-mail: asoalansantos@gmail.com \\ Lívia Maria da Silva Santos \\ Universidade Federal da Paraíba- UFPB \\ E-mail: livia.marias@hotmail.com \\ Jane Kelly Batista Ramalho Pedroza \\ Universidade Federal da Paraíba- UFPB \\ E-mail: janekramalho@hotmail.com \\ Marília Gabrielly Santos de Souza \\ Centro Universitário de João Pessoa- UNIPÊ \\ E-mail: mariliagabrielly2018@gmail.com
}

\section{RESUMO}

Esta pesquisa teve como objetivo verificar quais são os instrumentos gerenciais utilizados pelas empresas de peças e acessórios automotivos, localizadas na cidade de Bayeux/PB, na tomada de decisão. Para isso, foram constatadas 123 empresas abrangentes nesse setor, e, como amostra, 31 respondentes. Os dados foram coletados a partir de um questionário estruturado, e a pesquisa teve abordagem predominantemente quantitativa. Na organização dos dados, o estudo utilizou a estatística descritiva. Os resultados constataram que as empresas focam a tomada de decisão baseada na experiência do proprietário; ressalva-se, também, que grande parte das organizações não utiliza a contabilidade na tomada de decisão, pelo fato da informação contábil não refletir a real situação da empresa e/ou o gestor desconhecer sua utilidade. Os instrumentos gerenciais mais empregados na tomada de decisão são os controles operacionais, planejamento tributário e estratégico, e os menos utilizados são as demonstrações contábeis, métodos de custeio e outros instrumentos gerenciais. Conclui-se que, apesar de certa resistência dos gestores em querer gerenciar a organização com a própria intuição ou experiência, percebe-se que há a utilização de alguns instrumentos gerenciais.

Palavras-chave: Instrumentos gerenciais; Tomada de decisão; Contabilidade Gerencial. 


\begin{abstract}
This research aimed to verify which are the management instruments used by automotive parts and accessories companies, located in the city of Bayeux / PB, in decision making. For this, 123 comprehensive companies were found in this sector and, as a sample, 31 respondents. Data were collected from a structured questionnaire, and the research had a predominantly quantitative approach. In the data organization, the study used descriptive statistics. The results found that companies focus on decision making based on owner experience; It is also noted that most organizations do not use accounting in decision making, because the accounting information does not reflect the actual situation of the company and / or the manager is unaware of its usefulness. The most widely used managerial instruments in decision making are operational controls, tax and strategic planning, and the least used are the financial statements, costing methods and other management instruments. It is concluded that, despite some resistance of managers to want to manage the organization with their own intuition or experience, it is clear that there is the use of some management tools.
\end{abstract}

Keywords: Management Instruments; Decision making; Management accounting.

\title{
1. INTRODUÇÃO
}

As empresas concorrem em uma relação de mercado onde necessitam de conhecimentos precisos e organização dos seus negócios, para ajustar suas negociações às situações do mercado. O processo de tomada de decisão deve ser fundamentado em ferramentas e instrumentos gerenciais que ofereçam informações confiáveis e relevantes que subsidiem o processo decisório.

A tomada de decisão, segundo Oliveira (2004), é a conversão das informações analisadas em ação. Os gestores, diante dos desafios impostos, buscam informações que reflitam, precisamente, a efetiva conjuntura das organizações, para que o processo decisório seja efetuado de forma eficaz, para alcançar os resultados pretendidos. Neste sentido, pode-se entender que as decisões precisam ser tomadas de forma ágil e correta, pois o desempenho das organizações depende da qualidade de seu gerenciamento. Conforme Oro e Klann (2017) mencionam, esse processo envolve a necessidade de estimar, mensurar, reconhecer, estabelecer critérios e utilizar instrumentos, a fim de que os direcionamentos estratégicos possam ser atendidos.

Os instrumentos gerenciais contábeis têm como um de seus principais objetivos influenciar a melhor tomada de decisão, sendo indispensáveis para todo tipo de organização. Não obstante, a falta de habilidade para entender e manusear os instrumentos fornecidos pela Contabilidade nas Micro e Pequenas Empresas (MPEs) é uma das dificuldades encontradas em muitas pesquisas (Sheldon, 1994; Morais, 1999; Alburquerque, 2004; Lucena, 2004; Miranda, Libonati, Freire, \& Saturnino, 2008; Santos, Dorow \& Beuren, 2016.), e isso acaba por gerar uma cultura de não aproveitamento da informação contábil nessas empresas.

Conforme afirmam Sales, Barros e Araujo (2011), a não aplicação das informações contábeis e a baixa presença de assistência, ou assessoria de um contador, são fatores condicionantes à mortalidade precoce de pequenos empreendimentos. Para o Serviço Brasileiro de Apoio às Micros e Pequenas Empresas [SEBRAE] (2014), após uma pesquisa realizada com 526 organizações, constatou-se que $8 \%$ das empresas chegam a sua mortalidade antes de seus 5 anos de desenvolvimento, devido ao mal planejamento/administração. Além disso, verifica-se que as pequenas e médias empresas possuem uma representatividade 
importante em relação ao número de carteiras assinadas no Brasil, consequentemente, possuem um grande potencial de geração de empregos, além de sua representatividade e contribuição para o PIB nacional, considerando que em termos de quantidade, assumem a posição de possuírem $99 \%$ de representação como PMEs.

Portanto, é relevante que as informações contábeis sejam insights aos gestores, no formato desejado e no momento devido. $\mathrm{O}$ valor de uma informação está diretamente ligado com o modo pelo qual ela auxilia os tomadores de decisões a atingirem as metas e objetivos da organização. Uma organização, sem uma estrutura correta e sem conhecimento de seus atos e fatos contábeis, encontra dificuldades de competitividade no mercado em função da falta de informações fidedignas que auxiliam a tomada de decisão.

Os indícios empíricos, quanto à importância e uso dos instrumentos gerenciais, como um melhor planejamento estratégico, redução de custos e aumento de lucratividade, demonstraram, em sua maioria, que causam efeitos relevantes e a rotina das empresas torna-se mais formalizada e sistemática (Drury, \& Tayles, 1995; Innes, Mitchell, \& Sinclair, 2000; Beuren, Barp, \& Filipin, 2013; Santos et al., 2016).

Neste sentido, a presente pesquisa apresenta o seguinte questionamento: Quais instrumentos gerenciais são utilizados pelas empresas de peças e acessórios automotivos, localizadas na cidade de Bayeux/PB, na tomada de decisão?

Com isso, o objetivo desta pesquisa é verificar quais instrumentos gerenciais são utilizados pelas empresas de peças e acessórios automotivos, localizadas na cidade de Bayeux/PB, na tomada de decisão. Quanto ao objetivo específico, busca-se verificar o grau de importância atribuído pelos gestores aos instrumentos da contabilidade gerencial para a tomada de decisão.

A escolha do tema foi ocasionada no sentido de destacar a importância das práticas gerenciais, uma vez que as informações fornecidas podem se tornar um diferencial competitivo e um fator de sobrevivência dentro das organizações; além disso, por apresentar uma realidade específica em MPEs no setor de comércio na cidade de Bayeux, município da região metropolitana de João Pessoa.

\section{REFERENCIAL TEÓRICO}

\subsection{Processo de tomada de decisão}

Os desafios impostos pelas atividades diárias levam os gestores a buscar informações que reflitam, precisamente, a real situação das organizações, para que a tomada de decisão seja efetuada de forma eficaz, e, assim, seja possível alcançar os resultados planejados. Neste sentido, entende-se que as decisões precisam ser tomadas de forma ágil e eficiente, pois o funcionamento das organizações depende da qualidade de seu gerenciamento. Conforme Oro e Klann (2017) mencionam, o processo de tomada de decisão envolve a necessidade de estimar, mensurar, reconhecer e estabelecer critérios.

Figueiredo e Caggiano (1997, p. 33-34) consideram que "o processo de tomada de decisão é uma sequência lógica de etapas que externam a racionalidade com a qual os gestores buscam soluções para os problemas da organização". Após a problematização definida, o gestor, através das informações e relatórios, analisará a situação para poder mensurar o grau de risco encontrado, assim, poderá orientar a gestão sobre a melhor opção de extinguir ou retificar os erros, mediante o processo de tomada de decisão, para que a organização possa alcançar os objetivos anteriormente traçados. O processo decisório nas organizações convertese na habilidade gerencial, em que a responsabilidade do gestor é decidir a melhor possibilidade para cada momento em que se encontra a entidade, de modo a garantir os 
resultados prováveis. As atitudes aplicadas pelo gestor adquirem significância em todas as etapas do processo decisório, para que possa haver sintonia entre os objetivos almejados e os resultados realizados pela organização.

Tomar decisão vai além de um simples veto ou aprovação, é necessário ter conhecimento suficiente de todos os processos que possam influenciar os resultados do acontecimento em questão. Machado, Rapé e Souza (2015) enfatizam a importância da utilização, pelos administradores, dos sistemas de informação gerencial, que permitem o correto comando, controle e coordenação do ciclo gerencial. Observa-se que o processo decisório é, em si, um processo que não envolve apenas fatores objetivos, mas também fatores subjetivos. Esse processo engloba distintas variáveis que irão influenciar na escolha da melhor decisão ou da decisão mais adequada, a partir análises e ponderações necessárias a esse processo.

Pesquisas sobre a relação da informação contábil gerencial atrelada à tomada de decisão vêm sendo realizadas periodicamente, envolvendo objetos de estudos específicos e amostras diferenciadas, como: a utilização das informações geradas pelo sistema de informação contábil como subsídio aos processos administrativos (Oliveira, Muller, \& Nakamura, 2000); a importância das informações contábeis no processo decisório (Lima, Chacon, \& Silva, 2004; Nunes \& Serrasqueiro, 2004); gestão estratégica das informações internas (Albuquerque, 2004); identificação das necessidades de informações contábeis para a tomada de decisão organizacional. (Stroeher \& Freitas, 2006); demanda por serviços contábeis (Miranda et al., 2008); a influência da oferta de contabilidade gerencial na percepção da qualidade dos serviços contábeis prestados (Caneca, Miranda, Rodrigues, Libonati, \& Freire, 2009).

Krafta e Freitas (2008) apontaram que os pontos fracos nas organizações podem ser melhorados através da melhor gestão da informação, com base em dados que, já estão disponíveis para acesso na empresa, mas que não são aproveitados de forma adequada. Por fim, Silva, Miranda, Freire e Anjos (2010) buscaram evidências de como a informação contábil pode ser utilizada. Averiguou-se que, na maioria dos casos, os relatórios disponibilizados não são utilizados pelos gestores para acompanhar metas, avaliar desempenhos e medir impactos financeiros de suas decisões.

\subsection{Instrumentos gerenciais}

Um dos principais objetivos dos instrumentos gerenciais contábeis é influenciar a melhor tomada de decisão. Esses instrumentos são necessários para todo tipo de organização. Tais instrumentos, além de fornecer aos gestores informações que os auxiliam nas suas funções gerenciais, contribuem para assegurar a sobrevivência da organização.

Beuren et al. (2013) defendem que, com a utilização dos instrumentos de contabilidade gerencial no processo decisório, a vida cotidiana das empresas torna-se mais formalizada e sistemática. Influenciando assim, as atividades rotineiras e facilitando processos e o desenvolvimento organizacional.

Souza (2007) alega que o empresário deve atuar como administrador financeiro e contador gerencial, controlando estoques, contabilizando custos, produzindo planilhas para apurar seus resultados e decidindo sobre investimentos e financiamentos. Dentre os instrumentos básicos que a contabilidade pode gerar para a tomada de decisão, estão: controle de estoque, demonstração do fluxo de caixa, controle de contas a receber, controle de contas a pagar, controle de bancos e análise do resultado.

Há uma variedade de pesquisas e estudos ligados à utilização dos instrumentos gerenciais, seja nacional (Santana, Ciupak, Kuhn \& Tisott, 2007; Oyadomari, Cardoso, 
Mendonça \& Lima, 2008; Carvalho \& Lima, 2011; Anjos, Miranda, Silva \& Freitas, 2012; Santos, et al., 2016; Azevedo, Lima, Lucena \& Santos, 2017; Moreira, Gonçalves, Costa \& Ferreira, 2017) ou internacional (Drury \& Tayles, 1995; Innes et al., 2000; Baines \& Langfield-Smith, 2003; Lohr, 2012; Švárová \& Vrchota, 2013).

Nos estudos internacionais, Lohr (2012) analisou empresas industriais alemãs, e constatou que as atividades da contabilidade gerencial são limitadas nestas empresas por dois motivos principais: os benefícios não compensam os custos; e, a posição de mercado da empresa tem sido forte, sem contabilidade gerencial. Švárová e Vrchota (2013) relacionaram a gestão estratégica com o sucesso financeiro de pequenas e médias empresas da República Checa. Os resultados revelaram que as MPEs apresentaram melhores resultados de saúde financeira, comparativamente com empresas sem uma estratégia definida.

No tocante aos estudos nacionais, Santana et al. (2007) realizaram sua pesquisa com MPEs. Os resultados mostraram que os empresários não conhecem os instrumentos gerenciais, e que seus contadores fazem, apenas, a contabilidade tradicional, não lhes oferecendo suporte para a tomada de decisão. Por fim, Carvalho e Lima (2011) analisaram as práticas gerenciais utilizadas pelas MPEs do setor de confecções da cidade de Sousa/PB. Os resultados apontaram que os gestores utilizam de maneira informal os controles internos para a tomada de decisões, como o controle de contas a pagar, controle de caixa e controle de contas a receber.

\section{METODOLOGIA}

\subsection{Caracterização da pesquisa}

A pesquisa apresentada tem caráter descritivo, que tem por objetivo analisar, observar e relacionar fatos ou fenômenos sem intervenção; e exploratória, que é caracterizada pela especificidade das perguntas e o cenário pouco explorado.

\subsection{População e amostra}

A população da pesquisa englobou as empresas de peças e acessórios automotivos localizadas em Bayeux, região metropolitana da capital paraibana de João Pessoa-PB. Para determinação das empresas da população do estudo, verificou-se, junto à Prefeitura Municipal de Bayeux quais empresas estavam regularmente ativas, de modo que se obteve um total de 123 empresas, representando a população do estudo.

Um questionário foi encaminhado, via e-mail, para estas empresas, solicitando que fossem respondidas, fielmente, todas as perguntas, para obter a maior expressividade da realidade. Obteve-se resposta de 31 empresas, representando, então, a amostra do estudo.

\subsection{Instrumento da pesquisa}

Para o processo de coleta de dados, foi utilizado um instrumento de pesquisa, baseado nos estudos de Pires, Costa e Hahn (2004), Panucci Filho e Almeida (2011), Anjos et al. (2012), Moreira, Encarnação, Bispo, Angotti e Colauto (2013) e Santos et al. (2016). De modo que, visando atender os objetivos do estudo, estruturou-se o questionário em cinco partes.

A primeira parte do questionário foi elaborada e direcionada ao respondente, com o intuito de descobrir seu perfil, envolvendo perguntas como: a idade, escolaridade, gênero, 
função que ocupa na organização, formação e se possui conhecimento do resultado mensal da organização.

$\mathrm{Na}$ segunda parte do questionário verificou-se o perfil da empresa, o número de funcionários, tributação e estrutura hierárquica. A terceira parte do questionário solicitou, dos participantes da pesquisa, os responsáveis pelos setores de produção, financeiro e administrativo, e quem exerce o comando da empresa.

A quarta parte buscou detectar quais os procedimentos adotados para a tomada de decisão nas empresas, quais os recursos utilizados, qual a frequência de discussão do resultado da empresa com o contador, quais os meios de consulta para a tomada de decisões e quais os sistemas utilizados na elaboração de relatórios para a tomada de decisão.

A quinta parte do questionário procurou distinguir os instrumentos gerenciais aplicados pelas empresas no processo decisório. Foram divididos em: controles operacionais, demonstrações contábeis, métodos de custeio e outros instrumentos da contabilidade gerencial. Os questionamentos abordados sobre controles operacionais foram retirados da pesquisa de Lima et al. (2007); o modelo das demonstrações contábeis foram as mesmas relacionadas no estudo de Stroeher e Freitas (2008); e os métodos de custeio, e os outros instrumentos da contabilidade gerencial questionados, foram extraídos da pesquisa de Panucci Filho e Almeida (2011).

Ainda foi solicitado, aos respondentes, a atribuição de um posicionamento a respeito de: grau de importância das informações contábeis na empresa, grau de importância dos controles operacionais, grau de importância das demonstrações contábeis, e o grau de importância dos métodos de custeio. Isso foi solicitado para que se pudesse atender o objetivo específico da pesquisa. Utilizou-se então uma escala likert de cinco pontos, onde: (1) sem importância, (2) pouco importante, (3) comum, (4) importante e (5) muito importante. Ressaltando que, em todas as categorias, a opção (4) importante, teve maior êxito.

\subsection{Processo de análise dos dados}

A pesquisa realizada teve caráter quantitativo, utilizando-se da estatística descritiva para quantificar as informações do estudo, gerando medidas precisas, garantindo um melhor entendimento e padronização do resultado. Hayati, Karami e Slee (2006) afirmam que os estudos quantitativos buscam a existência de uma realidade que pode ser analisada com objetividade, pelo relacionamento de causa-efeito, a partir da utilização de métodos quantitativos de investigação, que permitem chegar a verdades universais.

Freund e Simon (2000), defendem que a estatística descritiva possui limitações ligadas ao fato de os dados serem, na maioria das vezes, obtidos de amostras, o que incita generalizações por parte do analista. A estatística descritiva é a etapa inicial da análise que permite compreender, descrever, resumir e interpretar os aspectos importantes de um conjunto de características observadas. Entre as ferramentas utilizadas pela estatística descritiva, podese citar gráficos e tabelas, e, também, medidas como porcentagens, índices e médias.

Utilizou-se a frequência para registrar a quantidade de vezes que determinada ação ocorreu. Para que os dados se tornem significativos, deve-se recorrer à frequência relativa da pesquisa, sendo esta feita através de dados percentuais, definidos como a razão entre a frequência absoluta e o número total de observações. 


\section{DESCRIÇÃO E ANÁLISE DOS RESULTADOS}

\subsection{Perfil dos respondentes das empresas}

A Tabela 1 apresenta os resultados do perfil dos respondentes das empresas referentes ao quesito de escolaridade e evidencia a área acadêmica em que os respondentes obtiveram formação.

Tabela 1

Escolaridade e formação dos respondentes

\begin{tabular}{|c|c|c|c|}
\hline Escolaridade & \multicolumn{2}{|c|}{ Freq. (\%) } & Total (\%) \\
\hline Ensino fundamental incompleto & \multicolumn{2}{|c|}{$0 \%$} & \multirow{7}{*}{$100 \%$} \\
\hline Ensino fundamental completo & \multicolumn{2}{|c|}{$0 \%$} & \\
\hline Ensino médio incompleto & \multicolumn{2}{|c|}{$0 \%$} & \\
\hline Ensino médio completo & \multicolumn{2}{|c|}{$22,60 \%$} & \\
\hline Ensino superior incompleto & \multicolumn{2}{|c|}{$25,80 \%$} & \\
\hline Ensino superior completo & \multicolumn{2}{|c|}{$45,20 \%$} & \\
\hline Especialização & \multicolumn{2}{|c|}{$6,50 \%$} & \\
\hline Área de formação & SIM & NÃO & Total (\%) \\
\hline Administração & $22,60 \%$ & $77,40 \%$ & $100 \%$ \\
\hline Ciências Contábeis & $32,30 \%$ & $67,70 \%$ & $100 \%$ \\
\hline Economia & $12,90 \%$ & $87,10 \%$ & $100 \%$ \\
\hline Recursos Humanos & $3,20 \%$ & $96,80 \%$ & $100 \%$ \\
\hline Nenhum & $25,00 \%$ & $75,00 \%$ & $100 \%$ \\
\hline Técnico Contabilidade & $3,20 \%$ & $96,80 \%$ & $100 \%$ \\
\hline Gestão Financeira & $3,20 \%$ & $96,80 \%$ & $100 \%$ \\
\hline Nenhum & $25,80 \%$ & $74,20 \%$ & $100 \%$ \\
\hline
\end{tabular}

Fonte: Dados da pesquisa (2017).

Na Tabela 1, pode-se evidenciar que $22,60 \%$ dos gestores possuem o ensino médio completo. O grau de escolaridade predominante é o de ensino superior completo, representando 45,20\%, o que pode implicar o fácil desenvolvimento de competências organizacionais. Verificou-se, ainda, que $6,50 \%$ estão buscando aprimorar seu conhecimento, por meio de uma especialização. Nenhum respondente possui ensino fundamental e médio incompletos.

$\mathrm{Na}$ área de formação, pode-se perceber a formação de apenas um gestor em mais de uma graduação, onde destaca-se o curso de Ciências Contábeis com 32,30\% seguido pelo curso de administração, com 22,60\%. Aparece, também, o curso técnico em contabilidade e o de gestão financeira, ambos com um percentual de 3,20\%. A opção "Nenhum" foi percebida com $25,80 \%$ de representatividade, isso pode se explicar pelo fato de que alguns gestores ainda não concluíram sua graduação. gestão.

A Tabela 2 demonstra a frequência em que os respondentes buscam realizar cursos de 
Tabela 2

Frequência de realização de cursos de gestão

\begin{tabular}{l|c|c|c}
\hline Realização de cursos de gestão & SIM & NãO & Total (\%) \\
\hline Frequentemente & $0,00 \%$ & $100 \%$ & $100 \%$ \\
\hline Com pouca frequência & $3,20 \%$ & $96,80 \%$ & $100 \%$ \\
\hline Raramente & $9,70 \%$ & $90,30 \%$ & $100 \%$ \\
\hline Nunca & $87,10 \%$ & $12,90 \%$ & $100 \%$ \\
\hline
\end{tabular}

Fonte: Dados da pesquisa (2017).

Ao analisar a Tabela 2, enfatiza-se, como relevante o fato de que $87,10 \%$ nunca buscaram realizar um curso de gestão. A busca por conhecimentos é uma forma de crescimento e o caminho para o sucesso do gestor, o que possibilita desenvolver suas habilidades e a qualidade de seu serviço.

$\mathrm{Na}$ Tabela 3, pode-se constatar a representação da função que os respondentes ocupam nas empresas do setor de peças e acessórios automotivos.

Tabela 3

Função dos respondentes

\begin{tabular}{|c|c|c|c|}
\hline Função que ocupa na empresa & SIM & NÃO & Total (\%) \\
\hline Administrador (a) & $51,60 \%$ & $48,40 \%$ & $100 \%$ \\
\hline Diretor & $19,40 \%$ & $80,60 \%$ & $100 \%$ \\
\hline Setor Financeiro & $67,70 \%$ & $32,30 \%$ & $100 \%$ \\
\hline Gestor de projetos & $0,00 \%$ & $100,00 \%$ & $100 \%$ \\
\hline $\mathrm{RH}$ & $3,20 \%$ & $96,80 \%$ & $100 \%$ \\
\hline Sócio gerente & $12,90 \%$ & $87,10 \%$ & $100 \%$ \\
\hline
\end{tabular}

Fonte: Dados da pesquisa (2017).

A Tabela 3 representa o percentual da atuação dos respondentes dentro das organizações, sendo a maioria exercendo a função no setor financeiro $(67,70 \%)$ e em seguida os responsáveis pela administração $(51,60 \%)$, ressalvando que um gestor é responsável pelo setor financeiro, e pela administração.

$\mathrm{Na}$ Tabela 4, pode-se averiguar a noção do conhecimento dos respondentes a respeito do faturamento mensal da empresa.

Tabela 4

Conhecimento empresarial dos respondentes

\begin{tabular}{l|c|c}
\hline $\begin{array}{l}\text { Você tem conhecimento do resultado } \\
\text { mensal da empresa? }\end{array}$ & Freq. (\%) & Total (\%) \\
\hline Sim & $51,60 \%$ & $100 \%$ \\
\hline Não & $48,40 \%$ & \\
\hline
\end{tabular}

Fonte: Dados da pesquisa (2017).

A Tabela 4 evidencia que $51,60 \%$ dos respondentes possuem o conhecimento do resultado mensal da organização. O percentual de 48,40\% revelou que os respondentes não conhecem ou não tem acesso ao faturamento.

A Tabela 5 apresenta o resultado da faixa etária dos respondentes das empresas do setor de peças e acessórios automotivos, e, evidencia os resultados a respeito do gênero dos participantes do questionário realizado. 
Tabela 5

Faixa etária e Gênero dos respondentes

\begin{tabular}{l|c|c|c}
\hline Faixa Etária & SIM & NÃO & Total (\%) \\
\hline De 0 a 20 anos & $0 \%$ & $100,00 \%$ & $100 \%$ \\
\hline De 20 a 40 anos & $71 \%$ & $29,00 \%$ & $100 \%$ \\
\hline De 40 a 60 anos & $29 \%$ & $71,00 \%$ & $100 \%$ \\
\hline Acima de 60 anos & $0 \%$ & $100,00 \%$ & $100 \%$ \\
\hline Gênero & \multicolumn{2}{|c|}{ Freq. (\%) } & Total (\%) \\
\hline Masculino & \multicolumn{2}{|c|}{$61,30 \%$} & $100 \%$ \\
\hline Feminino & \multicolumn{2}{|c|}{$38,70 \%$} & \\
\hline
\end{tabular}

Fonte: Dados da pesquisa (2017).

$\mathrm{Na}$ Tabela 5 pode-se averiguar que os gestores possuem idade média entre 20 e 40 anos de idade, sendo representado com um percentual de $71 \%$, enquanto $29 \%$ dos respondentes possuem idade entre 40 e 60 anos. Pode-se afirmar dessa forma que o setor estudado é predominantemente jovem por ter dado oportunidades a gestores novos no mercado.

Ainda nesta tabela, destaca-se a predominância masculina no mercado. O percentual de $61,30 \%$ revela o sexo masculino e, $38,70 \%$, o sexo feminino, corroborando com o estudo de Madalozzo, Martins e Shiratori (2010), onde se averiguou o destaque masculino no mercado de trabalho, mas também defendeu, em seu estudo, o crescimento da mulher na área estudada.

\subsection{Perfil das empresas}

A Tabela 6 apresenta os resultados do perfil das empresas do setor de peças e acessórios automotivos.

Tabela 6

Perfil das empresas

\begin{tabular}{l|c|c|c}
\hline \multicolumn{1}{c|}{ Características } & (\%) & Total (\%) \\
\hline Regime de tributação & SIM & NÃO & $100 \%$ \\
\hline Simples Nacional & $74,20 \%$ & $25,80 \%$ & $100 \%$ \\
\hline Lucro Real & $25,80 \%$ & $74,20 \%$ & $100 \%$ \\
\hline Lucro Presumido & $0,00 \%$ & $100,00 \%$ & $100 \%$ \\
\hline Lucro Arbitrado & $0,00 \%$ & $100,00 \%$ & $100 \%$ \\
\hline Não conheço & $0,00 \%$ & $100,00 \%$ & $\mathbf{N} \%$ \\
\hline $\mathbf{N}^{\mathbf{0}}$ de funcionários & $\mathbf{S I M}$ & $\mathbf{N} \mathbf{O}$ & $100 \%$ \\
\hline Até 9 pessoas & $25,80 \%$ & $74,20 \%$ & $100 \%$ \\
\hline De 10 a 49 pessoas & $67,70 \%$ & $32,30 \%$ & $100 \%$ \\
\hline De 50 a 99 pessoas & $6,50 \%$ & $93,50 \%$ & $100 \%$ \\
\hline Acima de 100 pessoas & $0,00 \%$ & $100,00 \%$ & $\mathbf{N} \%$ \\
\hline Estrutura Hierárquica & $\mathbf{S I M}$ & $\mathbf{N A} \mathbf{O}$ & \\
\hline Dois níveis (direção geral e setores operacionais) & $64,50 \%$ & $35,50 \%$ & $100 \%$ \\
\hline Três níveis (Direção geral, departamentos e setores operacionais) & $35,50 \%$ & $64,50 \%$ & $100 \%$ \\
\hline Quatro níveis (Direção, diretoria, departamentos e setores) & $0 \%$ & $100,00 \%$ & $100 \%$ \\
\hline Classificação do desempenho & $\mathbf{S I M}$ & $\mathbf{N A ̃ O}$ & \\
\hline Acima da média & $3,20 \%$ & $96,80 \%$ & $100,0 \%$ \\
\hline Na média & $77,40 \%$ & $22,60 \%$ & $100,0 \%$ \\
\hline Abaixo da média & $0,00 \%$ & $100,00 \%$ & $100,0 \%$ \\
\hline Não sei informar & $19,40 \%$ & $80,60 \%$ & $100,0 \%$ \\
\hline Fonte Dado & &
\end{tabular}

Fonte: Dados da pesquisa (2017). 
A Tabela 6, no tocante ao regime de tributação, evidencia que $74,20 \%$ das empresas são cadastradas no Simples Nacional e $25,80 \%$ cadastradas no Lucro Real, não havendo nenhuma empresa que esteja enquadrada em outro regime de tributação. No que tange ao número de funcionários, as pequenas empresas representaram $67,70 \%$, por possuir até 49 funcionários, seguido das microempresas, pelo fato de conter até 9 funcionários $(25,80 \%)$, as médias empresas, por sua vez, demonstraram um total de $6,50 \%$ contendo entre 50 a 99 funcionários.

A respeito da estrutura hierárquica, $64,50 \%$ das organizações confirmaram que possuem dois níveis, sendo eles a direção geral e os setores operacionais, enquanto $35,50 \%$, afirmaram que a organização possui três níveis, entre eles: direção geral, departamentos e setores operacionais.

Indagou-se, também, sobre o posicionamento dos gestores a respeito de seu desempenho perante a concorrência. Dos respondentes, 3,20\% afirmaram que, comparado aos concorrentes, seu desempenho está acima da média; 77,40\% opinaram que seu desempenho está na média, e 19,40\% não souberam informar. O resultado deste estudo pode ser equiparado com o de Miranda et al. (2008), onde observou-se que 78,8\% das empresas veem seu desempenho na média, comparado com seus concorrentes.

\subsection{Divisão dos setores operacionais}

Na Tabela 7, pode-se observar a divisão dos setores operacionais das organizações.

Tabela 7

Divisão dos Setores Operacionais

\begin{tabular}{|c|c|c|c|}
\hline \multirow{2}{*}{$\begin{array}{l}\text { Setores } \\
\text { Comando/Administração }\end{array}$} & \multicolumn{2}{|c|}{$(\%)$} & \multirow[t]{2}{*}{ Total (\%) } \\
\hline & SIM & NÃO & \\
\hline Proprietário/sócio & $80,60 \%$ & $19,40 \%$ & $100 \%$ \\
\hline Administrador contratado & $45,20 \%$ & $54,80 \%$ & $100 \%$ \\
\hline Gerente & $22,60 \%$ & $77,40 \%$ & $100 \%$ \\
\hline Outro & $0,00 \%$ & $100,00 \%$ & $100 \%$ \\
\hline Financeiro & SIM & NÃO & \\
\hline Proprietário/sócio & $87,10 \%$ & $12,90 \%$ & $100 \%$ \\
\hline Administrador contratado & $32,30 \%$ & $67,70 \%$ & $100 \%$ \\
\hline Gerente & $22,60 \%$ & $77,40 \%$ & $100 \%$ \\
\hline Outro & $3,2 \%$ & $96,80 \%$ & $100 \%$ \\
\hline Produção & SIM & NÃO & \\
\hline Proprietário/sócio & $93,50 \%$ & $6,50 \%$ & $100 \%$ \\
\hline Administrador contratado & $16,10 \%$ & $83,90 \%$ & $100 \%$ \\
\hline Gerente & $29,00 \%$ & $71,00 \%$ & $100 \%$ \\
\hline Outro & $0,00 \%$ & $100,00 \%$ & $100 \%$ \\
\hline
\end{tabular}

Fonte: Dados da pesquisa (2017)

A Tabela 7 demonstra a divisão da organização em 03 setores. Observando-a é notório perceber que um mesmo gestor é responsável por várias funções organizacionais. Referente ao comando/administração da empresa $80,60 \%$ responderam que o proprietário era 
responsável pela função, corroborando assim, com o estudo de Santos et al. (2016), onde constatou-se que $92,68 \%$ de seus respondentes confirmaram que o responsável pelo comando/administração da empresa é desempenhado pelo proprietário. O mesmo acontece com o setor financeiro $(87,10 \%)$ e o controle da produção $(93,50 \%)$. As funções administrativas e financeiras em poucas empresas são exercidas por pessoas contratadas. Logo, os proprietários coordenam seus negócios, mesmo que sem alguma formação ou realização de cursos de gestão, deixando-se levar pela intuição.

\subsection{Procedimentos utilizados na tomada de decisão}

A Tabela 8 apresenta alguns procedimentos, e, também, demonstra a frequência de utilização dos mesmos para a tomada de decisão.

Tabela 8

Procedimentos utilizados para o processo de tomada de decisão

\begin{tabular}{|c|c|c|c|}
\hline \multirow{2}{*}{$\begin{array}{l}\text { Recursos utilizados } \\
\text {. }\end{array}$} & \multicolumn{2}{|c|}{$\begin{array}{l}\text { Utilizado na tomada de } \\
\text { decisão }(\%)\end{array}$} & \multirow[t]{2}{*}{ Total $(\%)$} \\
\hline & SIM & NÃO & \\
\hline Experiência do proprietário & $96,80 \%$ & $3,20 \%$ & $100 \%$ \\
\hline Informações fornecidas pela contabilidade & $51,60 \%$ & $48,40 \%$ & $100 \%$ \\
\hline Relatórios elaborados pelos gestores & $22,60 \%$ & $77,40 \%$ & $100 \%$ \\
\hline Intuição & $16,10 \%$ & $83,90 \%$ & $100 \%$ \\
\hline Outros Instrumentos & $0,00 \%$ & $100,00 \%$ & $100 \%$ \\
\hline Pessoas ou órgãos que recorrem para tomada de decisão & SIM & NÃO & \\
\hline Família & $0,00 \%$ & $100,00 \%$ & $100 \%$ \\
\hline Contador & $38,70 \%$ & $61,30 \%$ & $100 \%$ \\
\hline O dono toma as decisões sozinho & $100,0 \%$ & $0,00 \%$ & $100 \%$ \\
\hline Administrador externo à empresa & $0,00 \%$ & $100,00 \%$ & $100 \%$ \\
\hline SEBRAE & $3,20 \%$ & $96,80 \%$ & $100 \%$ \\
\hline Consultor & $0,00 \%$ & $100,00 \%$ & $100 \%$ \\
\hline Outros & $0,00 \%$ & $100,00 \%$ & $100 \%$ \\
\hline Sistemas utilizados & SIM & NÃO & \\
\hline Manual (papel) & $83,90 \%$ & $16,10 \%$ & $100 \%$ \\
\hline Planilha Excel & $96,80 \%$ & $3,20 \%$ & $100 \%$ \\
\hline Pacote multiusuário & $3,20 \%$ & $96,80 \%$ & $100 \%$ \\
\hline ERP & $0,00 \%$ & $100,00 \%$ & $100 \%$ \\
\hline Nenhum & $0,00 \%$ & $100,00 \%$ & $100 \%$ \\
\hline $\begin{array}{l}\text { Informações contábeis contribuem com os objetivos da } \\
\text { empresa? }\end{array}$ & SIM & NÃO & \\
\hline Nas decisões diárias & $3,20 \%$ & $96,80 \%$ & $100 \%$ \\
\hline Nas decisões estratégicas & $6,50 \%$ & $93,50 \%$ & $100 \%$ \\
\hline Nas decisões de financiamento & $3,20 \%$ & $96,80 \%$ & $100 \%$ \\
\hline Nas decisões de investimento & $3,20 \%$ & $96,80 \%$ & $100 \%$ \\
\hline $\begin{array}{l}\text { No acompanhamento dos negócios e atendimento da parte } \\
\text { legal }\end{array}$ & $96,80 \%$ & $3,20 \%$ & $100 \%$ \\
\hline
\end{tabular}




\begin{tabular}{l|c|c|c}
$\begin{array}{l}\text { Frequência que discute o resultado da empresa com o } \\
\text { contador }\end{array}$ & SIM & NÃo & \\
\hline Frequentemente & $0,00 \%$ & $100 \%$ & $100 \%$ \\
\hline Com pouca frequência & $32,30 \%$ & $67,7 \%$ & $100 \%$ \\
\hline Raramente & $12,90 \%$ & $87,10 \%$ & $100 \%$ \\
\hline Nunca & $54,80 \%$ & $45,20 \%$ & $100 \%$ \\
\hline Motivo da não utilização da contabilidade no apoio à gestão & SIM & Não & \\
\hline Desconhece as utilidades & $6,50 \%$ & $93,50 \%$ & $100 \%$ \\
\hline A informação contábil não reflete a realidade da empresa & $90,30 \%$ & $9,70 \%$ & $100 \%$ \\
\hline Falta de comunicação com o contador & $12,90 \%$ & $87,10 \%$ & $100 \%$ \\
\hline Dificuldade para interpretar os relatórios & $19,40 \%$ & $80,60 \%$ & $100 \%$ \\
\hline Fonte: Dad
\end{tabular}

Fonte: Dados da pesquisa (2017).

$\mathrm{Na}$ Tabela 8, evidencia-se os procedimentos utilizados na tomada de decisão, de modo que $96,80 \%$ dos respondentes confirmaram que a tomada de decisão organizacional é gerada através da experiência do proprietário, 51,60\% através de informações concedidas pela contabilidade, $22,60 \%$ por meio de relatórios elaborados pelos gestores, e $16,10 \%$ por meio da intuição, gerando perdas ou ganhos, e conflitos de valores. Os resultados do estudo realizado por Moreira et al. (2013) comprovaram também que a maior parte dos recursos utilizados para a tomada de decisão é gerada por conta do proprietário, comprovando que $64,4 \%$ acreditam na própria experiência.

Indagou-se sobre quais são as pessoas ou órgãos que os gestores recorrem para a tomada de decisão. Observou-se que $100 \%$ dos gestores acreditam que seu conhecimento possa sim ser a melhor saída para a melhor tomada de decisão, enquanto 38,70\% defendem que o contador seria o melhor meio de se tomar uma decisão.

Caneca et al. (2009), em seu estudo, constataram que muitos dos contadores pesquisados têm a interpretação de que maior parte de seus clientes nunca utiliza, em seu favor, as demonstrações contábeis, como ferramentas de suporte à tomada de decisão.

Questionou-se, também, se as informações contábeis contribuem com os objetivos da empresa; obteve-se $96,80 \%$ de respostas, em que concordaram que as informações contribuem, apenas, para o acompanhamento dos negócios legais e atendimento à parte legal. Anthony e Govindarajan (2002) defendem que as informações contábeis aplicadas ao controle gerencial têm o papel de planejar, coordenar, comunicar, avaliar, decidir e influenciar, fazendo, assim, um processo de aprimoramento de gestão organizacional, além de um mero atendimento de normas e regras legais.

Os sistemas utilizados, na maior das empresas pesquisadas são as planilhas eletrônicas $(96,80 \%)$, seguidos de planilhas manuais $(83,90 \%)$. Pode-se equiparar este resultado com o estudo de Panucci Filho e Almeida (2011), que constatou que a planilha eletrônica, como o Excel, é o sistema mais utilizado pelas organizações.

A frequência com que se discute o resultado da empresa com o contador foi outra questão abordada, reconhecendo que 54,80\% nunca discutem seus resultados com o contador tendo ele o poder de passar informações reais para a tomada de decisões, mostrar quais as melhores formas de crescimento, e que se adquiridas pelos gestores são de suma relevância e só tem a acrescentar á empresa. Verificou-se, também, que 32,30\% discutem o resultado com pouca frequência, e $12,90 \%$ raramente têm essa conversa com o contador. 


\subsection{Instrumentos da Contabilidade Gerencial}

A Tabela 9 apresenta os instrumentos gerenciais e demonstra a frequência de utilização dos mesmos.

Tabela 9

Instrumentos gerenciais

\begin{tabular}{|c|c|c|c|}
\hline \multirow{2}{*}{$\begin{array}{l}\text { Instrumentos } \\
\text { Controles operacionais }\end{array}$} & \multicolumn{2}{|c|}{ Utilizado na tomada de decisão (\%) } & \multirow[t]{2}{*}{ Total (\%) } \\
\hline & SIM & NÃO & \\
\hline Controle de caixa & $25,21 \%$ & $74,79 \%$ & $100 \%$ \\
\hline Controle de contas a pagar & $26,05 \%$ & $73,95 \%$ & $100 \%$ \\
\hline Controle de contas a receber & $26,05 \%$ & $73,95 \%$ & $100 \%$ \\
\hline Controle de estoques & $15,13 \%$ & $84,87 \%$ & $100 \%$ \\
\hline Controle de custos e despesas & $7,56 \%$ & $92,44 \%$ & $100 \%$ \\
\hline Demonstrações contábeis & SIM & NÃO & \\
\hline Balancete & $45,90 \%$ & $54,10 \%$ & $100 \%$ \\
\hline Balanço Patrimonial e DRE & $37,37 \%$ & $62,63 \%$ & $100 \%$ \\
\hline DVA & $8,20 \%$ & $91,80 \%$ & $100 \%$ \\
\hline DFC & $4,92 \%$ & $95,08 \%$ & $100 \%$ \\
\hline DMPL e DLPA & $1,64 \%$ & $98,36 \%$ & $100 \%$ \\
\hline Notas explicativas & $1,64 \%$ & $98,36 \%$ & $100 \%$ \\
\hline Métodos de Custeio & SIM & NÃO & \\
\hline Custeio por absorção & $35,00 \%$ & $65,00 \%$ & $100 \%$ \\
\hline Custeio variável & $15,00 \%$ & $85,00 \%$ & $100 \%$ \\
\hline Custeio padrão & $5,00 \%$ & $95,00 \%$ & $100 \%$ \\
\hline Custeio ABC & $10,00 \%$ & $90,00 \%$ & $100 \%$ \\
\hline Custo meta & $0,00 \%$ & $0,00 \%$ & $0 \%$ \\
\hline Desconheço & $35,00 \%$ & $65,00 \%$ & $100 \%$ \\
\hline Outros Instrumentos & SIM & NÃO & \\
\hline Retorno sobre investimento & $1,92 \%$ & $98,08 \%$ & $100,0 \%$ \\
\hline Orçamento & $57,69 \%$ & $42,31 \%$ & $100,0 \%$ \\
\hline Planejamento tributário & $19,23 \%$ & $80,77 \%$ & $100,0 \%$ \\
\hline Ponto de equilíbrio & $1,92 \%$ & $98,08 \%$ & $100,0 \%$ \\
\hline Planejamento estratégico & $19,23 \%$ & $80,77 \%$ & $100,0 \%$ \\
\hline
\end{tabular}

Fonte: Dados da pesquisa (2017).

A Tabela 9 demonstra que, entre os instrumentos da contabilidade gerencial indicados, destaca-se o uso para os controles operacionais, predominando o uso do controle de contas a pagar e o contas a receber, ambos representados por $26,05 \%$. Observou-se que $25,21 \%$ das empresas utilizam o controle de caixa, o que coaduna com Carvalho e Lima (2011), onde, nesse estudo, afirmam que estes controles operacionais são os mais utilizados em pequenas e microempresas.

Não obstante, Carvalho e Lima (2011) averiguaram, em seu estudo, as práticas gerenciais utilizadas pelas pequenas e microempresas do setor de confecções da cidade de Sousa/PB. Os resultados demonstraram um maior número de utilização desses instrumentos, comparado ao estudo presente, onde, 93,4\% indicaram ter controle de contas a receber e controle de caixa, e $97,8 \%$ das empresas possuem um controle de contas a pagar. 
No quesito das demonstrações contábeis, pôde-se verificar que as demonstrações contábeis que apresentaram maior utilização são o Balancete $(45,90 \%)$, Balanço Patrimonial juntamente com a Demonstração do Resultado do Exercício (DRE) (37,37\%), tendo o menor índice de utilização a Demonstrações das Mutações do Patrimônio Líquido (DMPL) e a Demonstrações dos Lucros e Prejuízos Acumulados (DLPA) e as Notas Explicativas (NE), ambas com (1,64\%). Esses resultados corroboram com o estudo de Silva et al. (2010), onde constataram que 36 empresas, dentre 55 pesquisadas $(65,4 \%)$, utilizam o Balanço Patrimonial e a DRE, resultando, assim, em um resultado superior ao deste trabalho.

Referente aos métodos de custeio, constatou-se que 35\% dos gestores não conhecem os métodos apresentados. Em contrapartida, o uso do custeio por absorção foi o mais utilizado, conforme observado no estudo de Maehler, Rodrigues e Cassanego Júnior (2006).

Em relação aos outros instrumentos gerenciais, certifica-se que a maioria das empresas reconhecem que o orçamento $(57,69 \%)$ e o planejamento estratégico e tributário ambos com $(19,23 \%)$, possam direcionar as estratégias e ações organizacionais.

\section{CONSIDERAÇÕES FINAIS}

A utilização de instrumentos gerenciais, como forma de apoio para uma melhor tomada de decisão nas organizações, se caracteriza como uma relevante ferramenta estratégica e um diferencial competitivo.

Desse modo, o objetivo deste trabalho foi verificar quais instrumentos gerenciais são utilizados pelas empresas de peças e acessórios automotivos, localizadas na cidade de Bayeux/PB, na tomada de decisão. O estudo foi realizado através de questionário eletrônico, que foi enviado às empresas, baseado nos estudos de Pires et al. (2004), Panucci Filho e Almeida (2011), Anjos et al. (2012), Moreira et al. (2013) e Santos et al. (2016).

Destaca-se, no perfil dos respondentes, que o grau de escolaridade predominante é o de ensino superior completo, o que pode implicar em sua gestão o fácil desenvolvimento de competências organizacionais. Os gestores, em sua maioria, ocupam a função de administrador e responsável pelo setor financeiro, ressalvando um gestor que ocupa as duas funções numa mesma organização. A respeito do conhecimento mensal da empresa, revela-se que a maior parte dos gestores possui esse conhecimento. A faixa etária prevalecente corresponde aos gestores entre 20 e 40 anos. A área de formação dos respondentes que se destaca é o curso de ciências contábeis, seguido pelo curso de administração. É interessante destacar a predominância masculina no mercado, e que a maioria dos gestores nunca buscou a realização de cursos de gestão.

No tocante ao perfil das empresas, evidencia-se como regime de tributação predominante, as empresas cadastradas no Simples Nacional, tendo, a maioria das organizações, a estrutura hierárquica constituída por dois níveis. Consideradas pequenas empresas, a categoria que mais prevaleceu foi a das empresas compostas por até 49 funcionários. Os gestores, em sua grande parte, confirmaram acreditar que a organização mantém seu desempenho na média, em relação aos seus concorrentes.

Pôde-se observar, a respeito da divisão dos setores operacionais das organizações que, os 3 setores abordados possuem o comando do proprietário, podendo perceber que um mesmo gestor é responsável por várias funções organizacionais.

Com relação aos procedimentos utilizados na tomada de decisão, maior parte dos respondentes confirmou que a tomada de decisão organizacional é gerada através da experiência do proprietário, sendo o contador procurado, apenas, para o acompanhamento dos negócios e atendimento da parte legal e fiscal, e pouco procurado para discussões sobre os resultados. 
Também foi possível, de acordo com os resultados da utilização dos instrumentos gerenciais, constatar a utilização dos controles operacionais em parte das empresas, instrumentos como: controle de caixa, controle de contas a pagar e controle de contas a receber, e o uso de outros instrumentos como o orçamento, planejamento tributário e estratégico. Os métodos de custeio são poucos utilizados pelo fato de grande parte dos gestores afirmarem que desconhecem tais métodos.

Portanto, pode-se concluir que os resultados deste estudo apresentam uma interpretação reduzida dos gestores ao verem a contabilidade apenas como instrumento para atender às exigências legais e fiscais, talvez, por ser uma prática recorrente do mercado, na localidade estudada. Observa-se ainda, que grande parte dos gestores tomam decisões baseadas na intuição, neste estudo chamado de "experiência", por ter dado certo em decisões anteriores. De fato, se as empresas desses gestores continuam no mercado, isso significa que sua intuição está correta, no entanto, decisões tomadas sem informações seguras são sempre arriscadas para a empresa. Talvez, esse seja o descompasso no uso da informação para a tomada de decisão, no grau de risco que cada gestor assume quando da tomada de decisão.

Em relação às limitações da pesquisa, podem ter influenciado, nos resultados deste estudo, a pequena amostra analisada, e também, o baixo nível de conhecimento, em certos questionamentos, de alguns gestores ao responder o questionário.

Como sugestões de futuras pesquisas, indica-se buscar, nas empresas prestadoras de serviços contábeis, os motivos do não empenho dos contadores em querer demonstrar interesse em prestar serviços gerenciais, não apenas enfatizando os aspectos legais. Recomenda-se, também, uma investigação em empresas de outros setores comerciais, para que se conheçam outras realidades, no que concerne ao uso dos instrumentos gerenciais.

\section{REFERÊNCIAS}

Albuquerque, A. F. (2004). Gestão estratégica das informações internas na pequena empresa: estudo comparativo de casos em empresas do setor de serviços hoteleiro da região de Brotas. Dissertação (Mestrado em Engenharia da Produção) - Curso de PósGraduação em Engenharia de Produção, Escola de Engenharia de São Carlos, Universidade de São Paulo, São Paulo, SP, Brasil.

Anjos, L. C. M., Miranda, L. C., Silva, D. J. C., \& Freitas, A. R. F. (2012). Uso da contabilidade para obtenção de financiamento pelas micro e pequenas empresas: um estudo a partir da percepção dos gestores. Revista Universo Contábil, 8(1), pp. 86-104.

Anthony, R. N., \& Gonvindarajan V. (2002). Sistemas de Controle Gerencial. São Paulo: Atlas.

Azevedo, Y. G. P., Lima, D. H. S., Lucena, E. R. F.C. V., \& Santos, J. V. J. (2017). Análise dos Artefatos Gerenciais utilizados pelos Food Trucks da cidade de Natal/Rn. Revista de Gestão, Finanças e Contabilidade, 7(3), pp. 105-126.

Baines, A., \& Langfield-Smith, K. (2003). Antecedents to management accounting change: a structural equation approach. Accounting, Organization and Society, 28(7-8), pp. 675698.

Beuren, I. M., Barp, A. D., \& Flipin, R. (2013). Barreiras e Possibilidades de Aplicação da Contabilidade Gerencial em Micro e Pequenas Empresas por Meio de Empresas de Serviços Contábeis. Contexto, 13(24), pp. 79-92.

Caneca, L. R., Miranda, L. C., Rodrigues, R. N., Libonati, J. J., \& Freire, D. R. (2009). A Influência da Oferta de Contabilidade Gerencial na Percepção da Qualidade dos Serviços Contábeis Prestados aos Gestores de Micro, Pequenas e Médias Empresas. Pensar Contábil, 11(43), pp. 35-44. 
Carvalho, J. R. M., \& Lima, M. (2011). Práticas Gerenciais Em MPE's Do Comércio De Confecções Da Cidade De Sousa-PB. Revista De Educação E Pesquisa Em Contabilidade (Repec), 5(3), pp. 48-68.

Drury, C., \& Tayles, M. (1995). Issues arising from surveys of management accounting practices. Management Accounting Review, 6(3), pp. 267-280.

Freund, J. E., \& Simon, G. A. (2000). Estatística aplicada. (9a ed.) Porto Alegre: Bookman.

Figueiredo, S., \& Caggiano, P. C. (1997). Controladoria Teoria e Prática. (2a ed.) São Paulo: Atlas.

Hayati, D., Karami, E., \& Slee, B. (2006). Combining qualitative and quantitative methods in the measurement of rural poverty. Social Indicators Research, 75, pp. 361-394.

Innes, J., Mitchell, F., \& Sinclair, D. (2000). Activity-based costing in the U.K.'s largest companies: a comparison of 1994 and 1999 survey results. Management Accounting Research, 11(3), pp. 349-362.

Krafta, L., \& Freitas, H. (2008). Ação comercial baseada na gestão da informação de uma pequena empresa de TI. Revista de Gestão da Tecnologia e Sistemas de Informação, 5(3), pp. 483-504.

Lima, M. R. S., Chacon, M. J. M., \& Silva, M.C. (2004). Uma contribuição a importância do fluxo de informações contábeis no processo decisório das micro e pequenas empresas: uma pesquisa realizada na cidade de recife no estado de Pernambuco. Anais da Conferência Internacional de Empreendedorismo Latino Americana. Rio de Janeiro, RJ, Brasil.

Lohr, M. (2012). Specificities of managerial accounting at SMEs: case studies from the German industrial sector. Journal of Small Business \& Entrepreneurship, 25(1), pp. 3555.

Lucena, W. G. L. (2004). Uma contribuição ao estudo das informações contábeis geradas pelas micro e pequenas empresas localizadas na cidade de Toritama no agreste pernambucano. Dissertação de mestrado de ciências contábeis, Programa Multiinstitucional e Inter-regional de Pós-graduação em Ciências Contábeis da UNB/ UFPE/ UFPB/ UFRN, João Pessoa, PB, Brasil.

Machado, J. R., Rapé, S. F. L., \& Souza, S. R. (2015). Contabilidade Gerencial e sua Importância para a Gestão e Tomada de Decisão das Empresas Contemporâneas. Revista Eletrônica de Administração \& Ciências Contábeis (Opet), 11, pp. 1-11.

Madalozzo, R., Martins, S. R., \& Shiratori, L. (2010). Participação no mercado de trabalho e no trabalho doméstico: homens e mulheres têm condições iguais? Revista Estudos Feministas, 18(2), pp. 547-566.

Maehler, A. E., Rodrigues, E. G, \& Cassanego Júnior, P. (2006). Utilização dos métodos de custeio como ferramenta decisória em organizações hospitalares. Anais do Simpósio de Engenharia de Produção, Bauru, SP, Brasil, 13.

Miranda, L. C., Libonati, J. J., Freire, D. R., \& Saturnino, O. (2008). Demanda por serviços contábeis pelos mercadinhos: são os contadores necessários? Contabilidade Vista \& Revista, 19(1), pp. 131-151.

Morais, E. F. C. (1999). Inteligência competitiva: estratégias para pequenas empresas. Brasília: GH comunicação gráfica Ltda.

Moreira, B. C. M., Gonçalves, M. V., Costa, M. F., \& Ferreira, A. C. (2017). Analisando o Uso de Instrumentos Financeiros nas Práticas de Gestão das Empresas do Setor de Confecção e Facção do Município de Formiga/MG. Revista da Micro e Pequena Empresa, 11(1), 87-107. 
Moreira, R.L., Encarnação, L.V., Bispo, O. N. A., Angotti, M., \& Colauto, R.D. (2013). A importância da informação contábil no processo de tomada de decisão nas micro e pequenas empresas. Revista Contemporânea de Contabilidade, 10 (19), pp. 119-140.

Nunes, L. C. F., \& Serrasqueiro, Z. M. S. (2004). A informação contabilística nas decisões financeiras das pequenas empresas. Revista Contabilidade \& Finanças, 15(36), pp. 8796.

Oliveira, A. G., Muller, A. N., \& Nakamura, W. T. (2000). A utilização das informações geradas pelo sistema de informação contábil como subsídio aos processos administrativos nas pequenas empresas. Revista FAE, 3(3), pp. 1-12.

Oliveira, D. P. R. (2004) Sistemas de informações gerenciais: estratégicas, táticas e operacionais. (9ed.) São Paulo: Atlas.

Oro, I. M., \& Klann, R. C. (2017). Avaliação da Capacidade de Julgamento \& Tomada Decisão Baseado nas Normas Internacionais de Contabilidade. Revista Catarinense de Ciências Contábeis, 16(47), pp .51-68.

Oyadomari, J. C. T., Cardoso, R. L., Mendonça, O. R., \& Lima, M. P. (2008). Fatores que influenciam a adoção de artefatos de controle gerencial nas empresas brasileiras. Um estudo exploratório sob a ótica da teoria neo-institucional. Revista de Contabilidade e Organizações, 2(2), pp. 55-70.

Panucci Filho, L., \& Almeida, L.B. (2011). A contabilidade gerencial no crescimento das organizações: um estudo nas indústrias de confecções. Revista Iberoamericana de Contabilidad de Gestión, 9(18), pp. 1-17.

Pires, M. A., Costa, F. M.; \& Hahn, A. V. (2004). Atendimento das necessidades de informação para a tomada de decisão em pequenas e médias empresas: análise crítica das informações geradas pela Contabilidade frentes aos seus objetivos - pesquisa exploratória no setor de confecções da Glória-ES. Anais do Simpósio Fucape De Produção Científica, Vitória, ES, Brasil.

Santana, A. F. B., Ciupak, C., Kuhn, I. N., \& Tisott, S. T. (2007). Diagnóstico e análise da utilização da contabilidade gerencial nas micro, pequenas e médias empresas da cidade de Cruz Alta - RS. Anais do Congresso Brasileiro De Custos, João Pessoa, PB, Brasil, 14.

Santos, V., Dorow, D. R., \& Beuren, I. M. (2016). Práticas Gerenciais de Micro e Pequenas Empresas. Revista Ambiente Contábil, 8(1), pp. 153-186.

Serviço Brasileiro de Apoio às Micros e Pequenas Empresas (2017). Causa Mortis - O sucesso e o fracasso das empresas nos primeiros 05 anos de vida. Recuperado em 18 outubro, 2017 , https://m.sebrae.com.br/Sebrae/Portal\%20Sebrae/UFs/SP/Pesquisas/causa_mortis_2014.p df.

Sheldon, D. (1994). Recognizing Failure Factors Helps Small Business Turnarounds. National Productivity Review, 13(4), p. 533-541.

Silva, D. J. C., Miranda, L. C., Freire, D. R., \& Anjos, L. C. M. (2010). Para que serve a informação contábil nas Micro e Pequenas Empresas? Revista Contemporânea de Contabilidade, 1(13), pp. 89-106.

Souza, L. E. (2008). Fundamentos de contabilidade gerencial: um instrumento para agregar valor. Curitiba: Juruá.

Stroeher, A. M., \& Freitas, H. (2006). Identificação das necessidades de informações contábeis de pequenas empresas para a tomada de decisão organizacional. Anais do Congresso Internacional de Gestão da Tecnologia e Sistemas de Informação - Contecsi, São Paulo, SP, Brasil, 3. 
Švárová, M.; \& Vrchota, J. (2013). Strategic management in micro, small and medium-sized businesses in relation to financial success of the enterprise. Acta Universitatis Agriculturae et Silviculturae Mendelianae Brunensis, 61(7), pp. 2859-2866. 